Check for updates

Cite this: Mater. Horiz., 2020, 7, 2460

DOI: $10.1039 / \mathrm{d} 0 \mathrm{mh} 90047 \mathrm{~h}$

rsc.li/materials-horizons

\section{Correction: Epoxy resin with exchangeable disulfide crosslinks to obtain reprocessable, repairable and recyclable fiber-reinforced thermoset composites}

\author{
Alaitz Ruiz de Luzuriaga, (D) Roberto Martin, Nerea Markaide, Alaitz Rekondo, \\ Germán Cabañero, Javier Rodríguez and Ibon Odriozola*
}

Correction for 'Epoxy resin with exchangeable disulfide crosslinks to obtain reprocessable, repairable and recyclable fiber-reinforced thermoset composites' by Alaitz Ruiz de Luzuriaga et al., Mater. Horiz., 2016, 3, 241-247, DOI: 10.1039/C6MH00029K.

The authors have detected an error in the calculation of the activation energy and vitrimer temperature. In Fig. 1b, log $\tau$ should be plotted on the $y$ axis instead of $\ln \tau$. Due to this error, the calculated activation energy is incorrect and the energy should be multiplied by $2.3(1 / \log e)$. The correct activation energy is $126.5 \mathrm{KJ} \mathrm{mol}^{-1}$ and the correct calculated vitrimer temperature is $75{ }^{\circ} \mathrm{C}$. The authors apologise for this error and state that this error does not affect any of the scientific findings and interpretations.

A detailed list of changes is provided as follows:

- The correct version of Fig. $1 \mathrm{~b}$ is shown below

- On page 243, "From this equation, an activation energy $\left(E_{\mathrm{a}}\right)$ of $55 \mathrm{~kJ} \mathrm{~mol}^{-1}$ was calculated for the dynamic epoxy network 5 . Such activation energy is lower than other reported systems..." should be changed to "From this equation, an activation energy $\left(E_{\mathrm{a}}\right)$ of $126 \mathrm{~kJ} \mathrm{~mol}^{-1}$ was calculated for the dynamic epoxy network 5. Such activation energy is similar to other reported systems..."

- On page 243, "For our dynamic epoxy system 5, the hypothetical $T_{\mathrm{v}}$ value obtained was $-13{ }^{\circ} \mathrm{C}$, which is well below its $T_{\mathrm{g}}$ $\left(127^{\circ} \mathrm{C}\right.$ from DSC)." should be changed to "For our dynamic epoxy system 5 , the hypothetical $T_{\mathrm{v}}$ value obtained was $75^{\circ} \mathrm{C}$, which is well below its $T_{\mathrm{g}}\left(127^{\circ} \mathrm{C}\right.$ from DSC)."

The Royal Society of Chemistry apologises for these errors and any consequent inconvenience to authors and readers. 


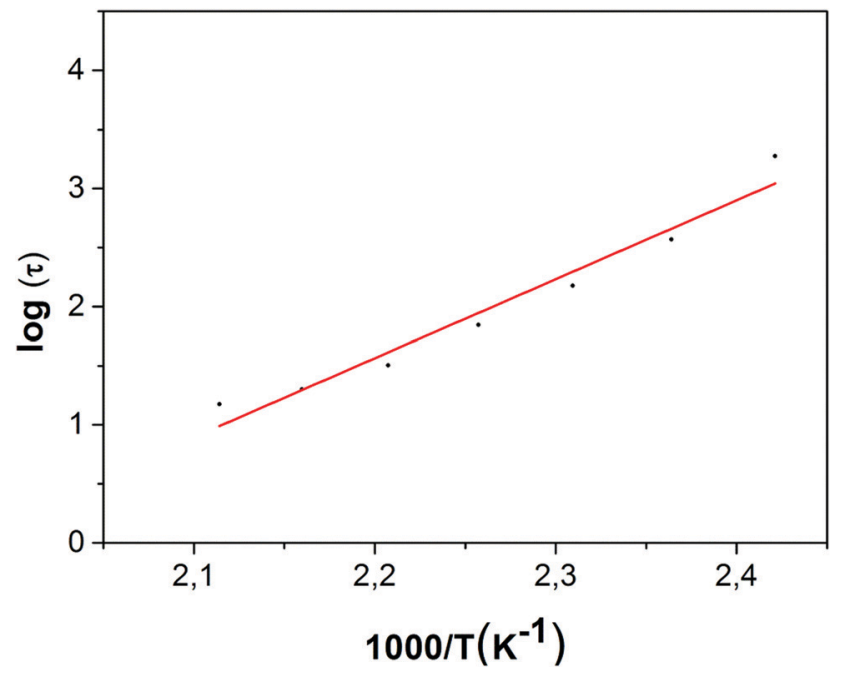

Fig. 1 (b) Fitting of the relaxation times to the Arrhenius' equation $(R$-square $=0.946)$. 